\section{Regulated Deficit Irrigation May Alter Apple Maturity, Quality, and Storage Life}

\author{
Robert C. Ebel ${ }^{1}$ and Edward L. Proebsting ${ }^{2}$ \\ Irrigated Agriculture Research and Extension Center, Washington State \\ University, Prosser, WA 99350
}

Max E Patterson ${ }^{2}$

Department of Horticulture and Landscape Architecture, Washington State University, Pullman, WA 99163

Additional index words. Malus domestica, ethylene, firmness, starch, acidity, color, soluble solids

\begin{abstract}
Delicious' apple (Malus domestica Borkh.) trees received regulated deficit irrigation (RDI) early in the growing season to determine if fruit quality and storage life would he altered compared to well-watered trees. Soil moisture and leaf water potential were lower in RDI trees than in those that did not receive RDI most of the season. Internal ethylene concentration increased logarithmically earlier in RDI apples. At harvest, RDI fruit were smaller and had a higher soluble solids concentration (SSC) and lower titratable acidity. Starch degradation was delayed in RDI fruit, and their color was not affected. Firmness was not affected when the effect of size on firmness was removed. The SSC of RDI apples remained higher during storage, but starch content, titratable acidity, firmness, and color were similar.
\end{abstract}

Plant water deficits and reduced wetted root volume have been studied to control the vegetative growth of commercial fruit trees (Chalmers et al., 1981; Ebel, 1991; Irving and Drost, 1987; Mitchell et al., 1984). Plant water deficits were manipulated by applying less water through irrigation than trees would have used, a method called regulated deficit irrigation (RDI) (Mitchell et al., 1984). Using RDI commercially to control vegetative growth requires an understanding of concomitant changes in fruit maturity, quality, and storage life.

Plant water deficits during the entire cellelongation phase of fruit growth can alter fruit quality and ethylene production (Guelfat-Reich et al., 1974). The current study was conducted to determine how RDI applied early in the cellelongation phase of fruit growth affects fruit maturity, quality, and storage life.

This study was conducted at Washington State Univ., Prosser, in south-central Wash-

Received for publication 27 Apr. 1992. Accepted for publication 12 Aug. 1992. Scientific paper no. 91-36, College of Agriculture Research Center, Washington State Univ., Pullman, WA 99164. This research was supported in part by a grant from the Washington Tree Fruit Research Commission. Statistical advice of John Schneider, Jerry Tangren, Arnold Saxton, and Rich Alldredge is gratefully acknowledged. The cost of publishing this paper was defrayed in part by the payment of page charges. Under postal regulations, this paper therefore must be hereby marked advertisement solely to indicate this fact.

'Postdoctoral Research Associate. Present address: Dept. of Ornamental Horticulture and Landscape Design, Univ. of Tennessee, P.O. Box 1071, Knoxville, TN 37901-1071.

${ }^{2}$ Horticulturist. ington. Average annual precipitation is 190 $\mathrm{mm}$, of which $\approx 50 \mathrm{~mm}$ falls during the MaySeptember growing season (Kleingartner, 1977).

An experimental block of 'Delicious' on seedling rootstocks was planted in 1973 with a tree spacing of $3.0 \times 4.5 \mathrm{~m}$. There were five rows, 23 trees per row, and the length of the block extended east to west. The soil was a Warden fine sandy loam that was uniform down the profile to fractured basalt bedrock. Field capacity (FC) was $28 \%$ and permanent wilting percentage (PWP) was $\approx 8.4 \%$, both by volume. Soil depth was $1.0 \mathrm{~m}$.

Trees were irrigated using a solid-set, overtree sprinkler system. Irrigation was scheduled from a United States Weather Bureau Class "A" evaporation pan $(\mathrm{E}$; pan coefficient = 0.80 ) and adjusted by a crop coefficient determined by the projected area of the canopy divided by the planting square area (James et al., 1982).

In 1983, the eastern half of the block received RDI by replacing daily $50 \% \mathrm{E}$ from 2 to 14 June, then $25 \% \mathrm{E}$ to $29 \mathrm{July}$, and the nondeficit level of $100 \% \mathrm{E}$ from 30 July through harvest. The western half of the block received water equal to $100 \% \mathrm{E}$ (control).

Soil moisture was determined by a neutron probe at $15-\mathrm{cm}$ increments along the profile via aluminum access tubes sunk to bedrock. Tubes were spaced 0.3 to $1.5 \mathrm{~m}$ from the trunk.

Four trees in each irrigation treatment were selected randomly and their leaf water potential (LWP), fruit ethylene, and fruit quality measured.

The LWP of five sunlit leaves was determined with a pressure bomb (Scholander et al., 1965). Leaves were excised between 0800 and $1400 \mathrm{HR}$, placed in a plastic bag, and kept at $0 \mathrm{C}$ until being measured within $5 \mathrm{~min}$ of being excised.

Internal ethylene concentration was determined using a modification of Williams and Patterson's method (1962). A 20-gauge needle with a septum-sealed sleeve was inserted through each apple calyx so that the tip protruded into the locule. Needles were inserted into 10 fruit per tree, four trees per treatment, 100 days after full bloom and were not removed until harvest.

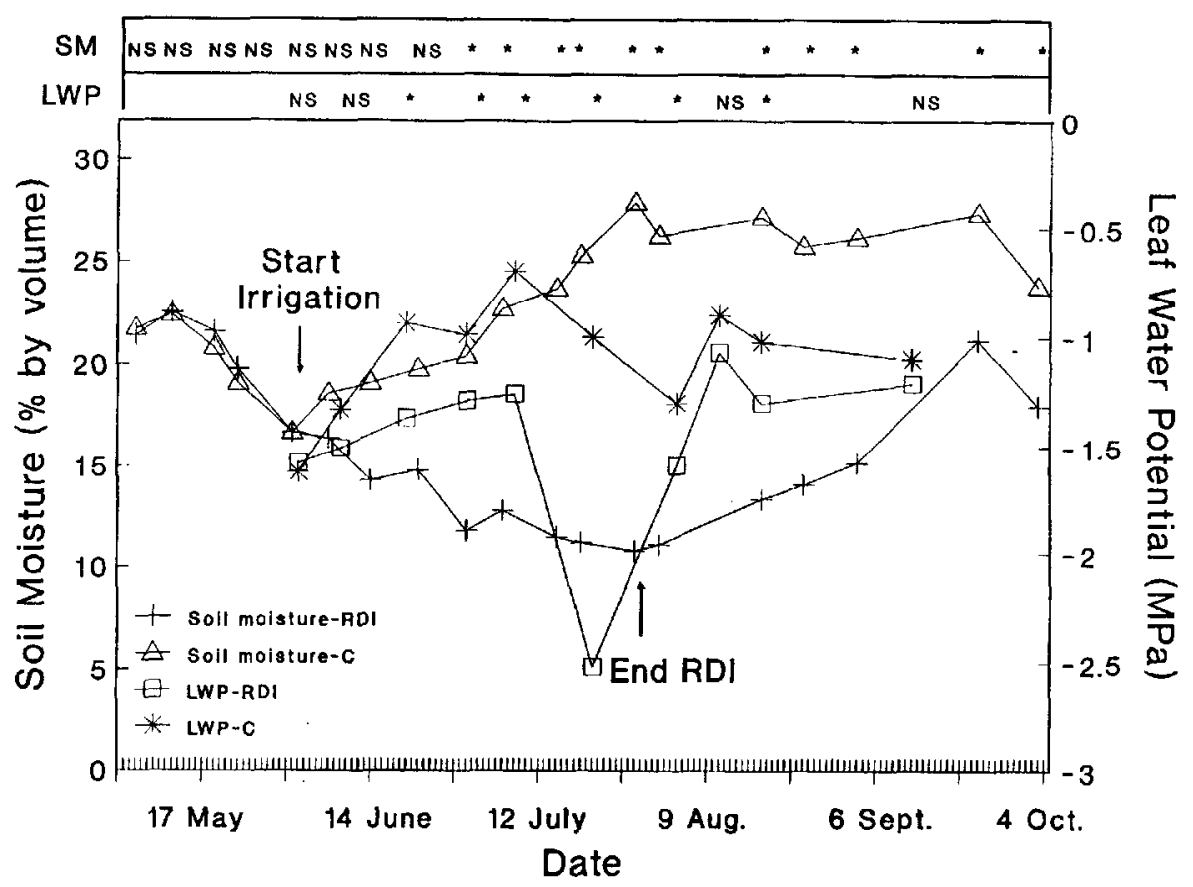

Fig. 1. Effect of regulated deficit irrigation (RDI) of apple trees on average soil moisture (SM) along the profile and leaf water potential (LWP) compared with a well-watered control (C).

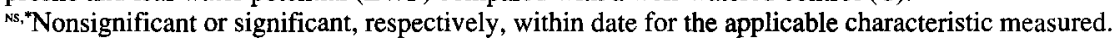


Gas samples were taken from the fruit locule by inserting a 1.0-ml syringe needle through the septum and into the sleeve of the 20 -gauge needle on four dates in September. After sampling, the needles were sealed in a rubber stopper,placed in a Styrofoam container, transported to the laboratory, and injected into a gas chromatograph fitted with a flame ionization detector. Ethylene was separated by a $0.32 \times 183-\mathrm{cm}$ stainless steel column packed with 60- to 80-mesh activated alumina.

Ten apples per tree were harvested on 8 , 18 , and 28 Sept. and 8 Oct., and quality characteristics were analyzed the same day. Additional apples were harvested 22 Sept. and stored in ambient atmosphere at $1 \mathrm{C}$. Ten fruit per tree were removed from storage each in November, December, January, and March and kept in ambient atmosphere at 20C for 12 $\mathrm{h}$ before quality characteristics were analyzed.

Apples were weighed, and skin color, firmness, starch content, soluble solids concentration (SSC), and titratable acidity were determined using the procedures of Drake et al. (1981). Starch was rated as $1=$ starch present in entire cross section, $2=$ core area clear of starch, 3 = area out to and including vascular bundles clear of starch, $4=$ area from the core halfway between the vascular bundles and skin clear of starch, $5=$ starch present just under skin, and $6=$ no starch present.

Analysis of variance was conducted on each measurement date for soil moisture and LWP data using the Statistical Analysis System's (SAS's) General Linear Models (GLM) procedure (SAS, 1988). Fruit quality characteristics at harvest and during storage were analyzed using a repeated measures model in SAS's GLM procedure (SAS, 1988). Since irrigation plots were not replicated, treatment variances were compared with in-plot variances.

Soil moisture and LWP declined during RDI and approached PWP and $-2.5 \mathrm{MPa}$, respectively, by the 3rd week in July (Fig. 1). The control's soil moisture and LWP were near FC and above $-1.5 \mathrm{MPa}$, respectively, during most of the growing season. Increasing RDI to replace $100 \%$ E starting 29 July resulted in a soil moisture gradient from FC near the surface to PWP at bedrock. The soil profile gradually filled with water from the surface down so that the entire profile was filled to near FC by harvest. LWP increased after RDI ended and nearly recovered to that of the control. Replacing 100\% E after RDI provided little more water than the trees were using and left some of the roots in dry soil the rest of the season.

Internal ethylene concentration was higher in RDI apples than in the control apples on each sampling date (Fig. 2). The SE of the mean was also larger for RDI apples, a result which indicated that a higher proportion of apples had entered the logarithmic rise in ethylene evolution. The higher ethylene concentration and increased SE of RDI apples are consistent with the physiology of an earlier-than-normal climacteric respiration rise (Meigh et al., 1967; Smock and Neubert, 1950).

The cumulative effect of increased plant water deficits indicated by lower LWP during and after RDI resulted in fruit that were $18 \%$ smaller and had a higher SSC, lower starch rating, and lower acid concentration than control fruit at harvest (Table 1).

A similar photosynthate loading rate into RDI fruit compared with control fruit possibly elevated SSC because the RDI fruit were smaller. However, advanced maturation and ripening, drought-induced osmotic adjustment, and RDI fruit dehydration contributed to SSC and acid content differences between irrigation treatments. During fruit development and maturation, SSC increases with a concomitant decrease in starch and acids (Smock and Neubert, 1950). Chalmers et al. (1986) and Davies and Lakso (1979) suggested that osmotic adjustment occurs in drought-stressed fruit. RDI fruit in the current study contained $85 \%$ water compared with $87 \%$ for control fruit (Ebel, 1985).

As fruit enter the climacteric respiration rise, acids and soluble carbohydrates from starch hydrolysis are needed to maintain the elevated respiratory rate during ripening. The lower acid content of RDI fruit, starting 18 Sept., is consistent with an earlier climacteric rise. However, the higher starch rating of control fruit on 18 and 28 Sept. suggests that starch hydrolysis began earlier in control fruit than in RDI fruit. Powell (1976) also found a higher fruit starch content in apples with high plant water deficits in June. The higher SSC in RDI fruit may be sufficient to maintain the accelerated respiratory rate and, thus, delayed starch hydrolysis.

RDI fruit were firmer than control fruit. Smaller fruit tend to be firmer because of higher cellular density. When RDI apple firmness was adjusted to remove the effect of size, there was no difference in firmness between irrigation treatments. Increased firmness of drought-stressed fruit has been reported previously (Guelfat-Reich et al., 1974; Haller and Harding, 1937; Powell, 1976), but in these studies the fruit were also smaller. It is not

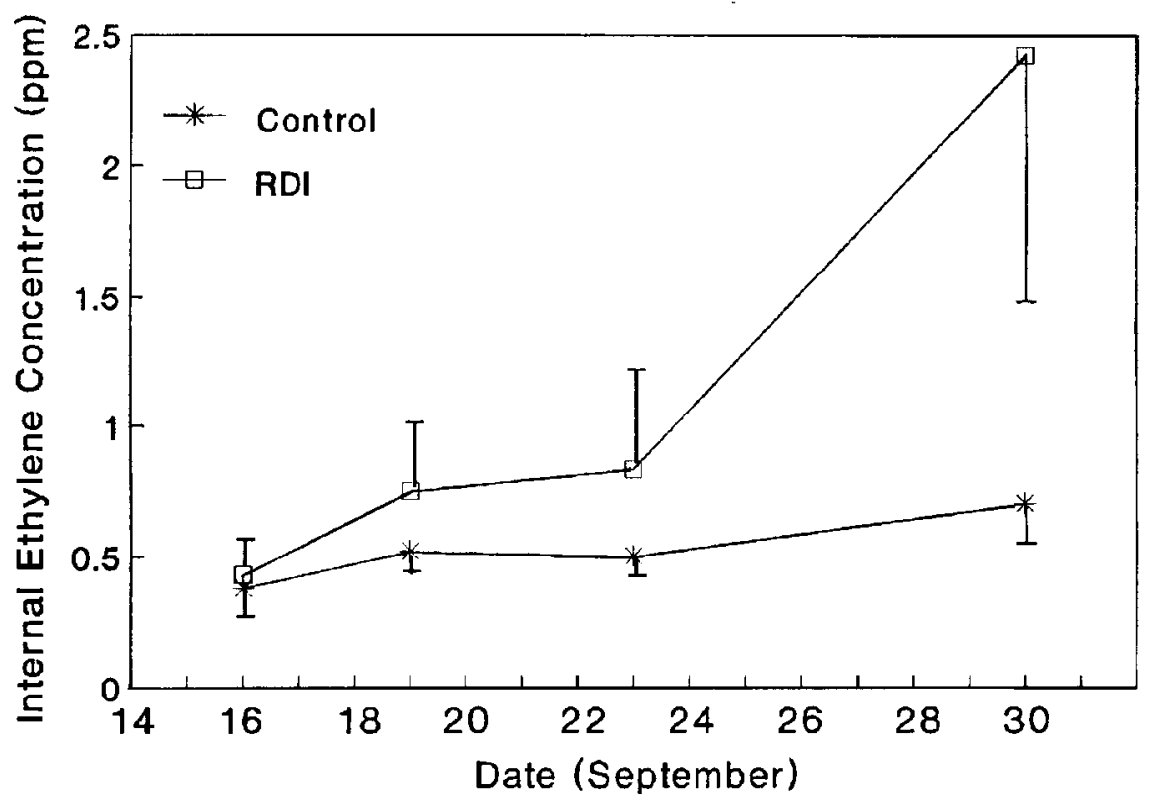

Fig. 2. Change in internal ethylene concentration during the harvesting period of apples attached to trees that received regulated deficit irrigation (RDI) compared with a well-watered control. Vertical bars represent one-half the SE of the mean. Each data point is the mean of 40 apples.

Table 1. Effect of regulated deficit irrigation (RDI) compared with a well-watered control (C) on fruit quality at harvest.

\begin{tabular}{|c|c|c|c|c|c|c|c|c|}
\hline \multirow[b]{2}{*}{ Date } & \multirow[b]{2}{*}{ Irrigation } & \multirow{2}{*}{$\begin{array}{l}W t \\
(g)\end{array}$} & \multirow{2}{*}{$\begin{array}{c}\text { Soluble } \\
\text { solids } \\
\text { concn }(\%)\end{array}$} & \multirow{2}{*}{$\begin{array}{l}\text { Starch } \\
\text { rating }\end{array}$} & \multicolumn{2}{|c|}{ Firmness (N) } & \multirow{2}{*}{$\begin{array}{l}\text { Red } \\
\text { color } \\
(\%)\end{array}$} & \multirow{2}{*}{$\begin{array}{c}\text { Malic } \\
\text { acid } \\
(\%) \\
\end{array}$} \\
\hline & & & & & Measured & Adjusted & & \\
\hline \multirow[t]{2}{*}{8 Sept. } & RDI & 125 & 9.9 & 1.4 & 80.9 & 76.2 & 86 & 0.34 \\
\hline & $\mathrm{C}$ & 154 & 8.3 & 1.4 & 74.7 & 71.5 & 86 & 0.34 \\
\hline \multirow[t]{2}{*}{18 Sept. } & RDI & 141 & 10.4 & 1.7 & 73.7 & 69.8 & 93 & 0.30 \\
\hline & $\mathrm{C}$ & 177 & 8.9 & 2.0 & 71.3 & 69.4 & 91 & 0.33 \\
\hline \multirow[t]{2}{*}{28 Sept. } & RDI & 141 & 12.4 & 2.6 & 71.7 & 68.2 & 92 & 0.29 \\
\hline & $\mathrm{C}$ & 182 & 10.4 & 3.3 & 68.4 & 66.8 & 91 & 0.34 \\
\hline \multirow[t]{2}{*}{8 Oct. } & RDI & 167 & 12.3 & 4.1 & 64.7 & 62.3 & 95 & 0.24 \\
\hline & $\mathrm{C}$ & 195 & 10.8 & 4.3 & 64.0 & 63.0 & 94 & 0.26 \\
\hline Treatment ( $\mathrm{T}$ ) & & $*$ & $*$ & $*$ & $*$ & NS & NS & * \\
\hline Date (D) & & $*$ & $*$ & $*$ & $*$ & $*$ & $*$ & * \\
\hline $\mathrm{T} \times \mathrm{D}$ & & NS & NS & $*$ & NS & NS & NS & NS \\
\hline
\end{tabular}

${ }^{2}$ Adjusted firmness determined with the equation: adjusted firmness $=$ firmness $+[0.054$ (apple weight) 11.557]. Equation developed with data from Bartram (1986).

Ns, ${ }^{*}$ Nonsignificant or significant at $P=0.05$, respectively. 
Table 2. Effect of regulated deficit irrigation (RDI) compared with a well-watered control(C) on fruit quality during storage. Fruit were harvested 22 Sept. and kept in ambient atmosphere at $1 \mathrm{C}$.

\begin{tabular}{|c|c|c|c|c|c|c|c|c|}
\hline \multirow{2}{*}{$\begin{array}{l}\text { Months in } \\
\text { storage }\end{array}$} & \multirow[b]{2}{*}{ Irrigation } & \multirow{2}{*}{$\begin{array}{l}W t \\
(\mathrm{~g})\end{array}$} & \multirow{2}{*}{$\begin{array}{c}\text { Soluble } \\
\text { solids } \\
\text { concn }(\%)\end{array}$} & \multirow{2}{*}{$\begin{array}{l}\text { Starch } \\
\text { rating }\end{array}$} & \multicolumn{2}{|c|}{ Firmness $(\mathrm{N})$} & \multirow{2}{*}{$\begin{array}{c}\text { Red } \\
\text { color } \\
(\%)\end{array}$} & \multirow{2}{*}{$\begin{array}{c}\text { Malic } \\
\text { acid } \\
(\%)\end{array}$} \\
\hline & & & & & Measured & Adjusted & & \\
\hline \multirow[t]{2}{*}{$\overline{2}$} & RDI & 152 & 12.4 & 3.9 & 71.3 & 68.0 & 95 & 0.24 \\
\hline & $\mathrm{C}$ & 186 & 10.6 & 4.4 & 69.8 & 68.3 & 94 & 0.25 \\
\hline \multirow[t]{2}{*}{3} & RDI & 150 & 12.5 & 5.3 & 62.4 & 59.0 & 95 & 0.21 \\
\hline & $\mathrm{C}$ & 177 & 11.3 & 5.4 & 64.2 & 62.2 & 95 & 0.23 \\
\hline \multirow[t]{2}{*}{4} & RDI & 147 & 13.1 & 5.3 & 56.5 & 52.9 & 95 & 0.19 \\
\hline & $\mathrm{C}$ & 174 & 11.5 & 5.4 & 59.5 & 57.4 & 94 & 0.21 \\
\hline \multirow[t]{2}{*}{5} & RDI & 154 & 12.2 & 5.9 & 53.1 & 49.9 & 94 & 0.13 \\
\hline & $\mathrm{C}$ & 175 & 10.6 & 5.9 & 53.8 & 51.7 & 94 & 0.15 \\
\hline Treatment $(\mathrm{T})$ & & $*$ & $*$ & NS & NS & NS & NS & NS \\
\hline Storage (S) & & NS & * & * & $*$ & * & NS & * \\
\hline$T \times S$ & & NS & NS & NS & NS & NS & NS & NS \\
\hline
\end{tabular}

${ }^{\mathrm{z}}$ Adjusted firmness determined with the equation: adjusted firmness = firmness $+[0.054$ (apple weight) 11.557]. Equation developed with data from Bartram (1986).

ss, Nonsignificant or significant at $P=0.05$, respectively.

known if differences in firmness were solely related to differences in size. Firmness decreases with maturation and softening rate increases during ripening (Smock and Neubert, 1950). The lack of an accelerated increase in RDI fruit softening may suggest that the physiological mechanism of softening is altered in drought-stressed fruit, even though maturity may be advanced. Irrigation did not affect the red color percentage of fruit skin.

Ethylene evolution, size, SSC, starch rating, acid concentration, firmness, and color are some of the characteristics used to determine optimum harvest date for long-term, controlled-atmosphere storage at Washington State Univ. (Bartram, 1986). Optimum harvest date is chosen by attaining quality characteristic target values and by evaluating their rate of change. Since all characteristics rarely reach the optimum target values on the same date, the optimum date is chosen when most of the characteristics reach the target value. Because of drought-induced physiological changes in the fruit, some of these characteristics may reach their target values on dates that differ from fruit of well-watered trees. For example, target values for internal ethylene concentration, SSC, and acid concentration were reached earlier and starch rating later in fruit from RDI trees than fruit from wellwatered trees.

RDI fruit continued to have higher SSC during storage (Table 2). Treatment differences in starch rating, acid concentration, and firmness not adjusted for size at harvest did not continue during storage. Also, there was no significant interaction with storage date. RDI fruit also had less storage scald (Ebel, 1985), a result that suggested advanced maturity at harvest.

In this study, RDI was severe and resulted in smaller fruit at harvest. The RDI fruit climacteric was probably earlier than that of control fruit, and fruit quality at harvest was altered. Except for size and SSC, fruit quality differences were not apparent during storage. Most commercial RDI applications will be at water deficit levels that do not reduce fruit size at harvest. However, RDI levels that reduce fruit growth may advance fruit maturity and alter quality at harvest.

\section{Literature Cited}

Bartram, R. 1986. Apple maturity program handbook. Apple Maturity Program, North Central Fieldmans Assn., Wenatchee, Wash.

Chalmers, D.J., G. Burge, P.H. Jerie, and P.D. Mitchell. 1986. The mechanism of 'Bartlett' pear fruit and vegetative growth by irrigation withholding and regulated deficit irrigation. J. Amer. Soc. Hort. Sci. 111(6):904-907.

Chalmers, D.J., P.D. Mitchell, and L. van Heek. 1981. Control of peach tree growth and productivity by regulated water supply, tree density, and summer pruning. J. Amer. Soc. Hort. Sci. 106(3):307-312.

Davies, F.S. and A.N. Lakso. 1979. Diurnal and seasonal changes in leaf water potential components and elastic properties in response to water stress in apple trees. Physiol. Plant. 46: 109-114. Drake, S.R., E.L. Proebsting, Jr., M.O. Mahan, and J.B. Thompson. 1981. Influence of trickle and sprinkle irrigation on 'Golden Delicious' apple quality. J. Amer. Soc. Hort. Sci. 106(2):255258.

Ebel, R.C. 1985. Postharvest physiology of 'Delicious' apples grown under deficit irrigation. MS Thesis, Washington State Univ., Pullman.

Ebel, R.C. 1991. Apple tree and fruit response to drought stress. PhD Diss., Washington State Univ., Pullman.

Guelfat-Reich, S., R. Assaf, B.A. Bravdo, and I. Levin. 1974. The keeping quality of apples in storage as affected by different irrigation regimes. J. Hort. Sci. 49:217-225.

Haller, M.H. and P.L. Harding. 1937. Relation of soil moisture to firmness and storage quality of apples. Proc. Amer. Soc. Hort. Sci. 35:205-211.

Irving, D.E. and J.H. Drost. 1987. Effects of water deficits on vegetative growth, fruit growth and fruit quality in Cox's Grange Pippin apple. J. Hort. Sci. 62:427-432.

James, L.G., J.M. Erpendbeck, D.L. Bassett, and J.E. Middleton. 1982. Irrigation requirements for Washington-Estimates and methodology. College of Agr. and Home Economics, Washington State Univ., Pullman, Coop. Ext. Bul. 1513.

Kleingartner, L.G. 1977. Data on weather from 1924-76. Irr. Agr. Res. Ext. Ctr.,Prosser, Wash., Ext. Bul. 858

Meigh,D.F., J.D. Jones, and A.C. Hulme. 1967. The respiration climacteric in the apple. Production of ethylene and fatty acids in fruit attached to and detached from the tree. Phytochemistry 6:1507-1515

Mitchell, P.D., B. van den Ende,P.H. Jerie, and D.J. Chalmers. 1989. Responses of 'Bartlett' pear to withholding irrigation, regulated deficit irrigation, and tree spacing. J. Amer. Soc. Hort. Sci. 114(1):15-19.

Mitchell, P.D., P.H. Jerie, and D.J. Chalmers. 1984. The effects of regulated water deficits on pear tree growth, flowering, fruit growth, and yield. J. Amer. Soc. Hort. Sci. 109(5):604-606.

Powell, D.B.B. 1976. Some effects of water stress on the growth and development of apple trees. J. Hort. Sci. 51:75-90.

SAS Institute. 1988. SAS/STAT user's guide. Release 6.03 ed. SAS Inst., Inc., Cary, N.C.

Scholander, P.F., J.T. Hammel, E.D. Bradstreet, and E.A. Hemmingsen. 1965. Sappressure in vascular plants. Science 148:339-345.

Smock, R.M. and A.M. Neubert. 1950. Apples and apple products. vol. I. Interscience, New York.

Williams, M.W. and M.E Patterson. 1962. Internal atmosphere in Bartlett pears stored in controlled atmospheres. Proc. Amer. Soc. Hort. Sci. 81:129136. 